San Jose State University

SJSU ScholarWorks

Master's Theses

Master's Theses and Graduate Research

1994

\title{
The relationship between mild to moderate hearing loss and academic achievement in reading in elementary school children
}

Maureen P. O'Hara

San Jose State University

Follow this and additional works at: https://scholarworks.sjsu.edu/etd_theses

\section{Recommended Citation}

O'Hara, Maureen P., "The relationship between mild to moderate hearing loss and academic achievement in reading in elementary school children" (1994). Master's Theses. 861.

DOI: https://doi.org/10.31979/etd.79ze-pt9q

https://scholarworks.sjsu.edu/etd_theses/861

This Thesis is brought to you for free and open access by the Master's Theses and Graduate Research at SJSU ScholarWorks. It has been accepted for inclusion in Master's Theses by an authorized administrator of SJSU ScholarWorks. For more information, please contact scholarworks@sjsu.edu. 


\section{INFORMATION TO USERS}

This manuscript has been reproduced from the microfilm master. UMI films the text directly from the original or copy submitted. Thus, some thesis and dissertation copies are in typewriter face, while others may be from any type of computer printer.

The quality of this reproduction is dependent upon the quality of the copy submitted. Broken or indistinct print, colored or poor quality illustrations and photographs, print bleedthrough, substandard margins, and improper alignment can adversely affect reproduction.

In the unlikely event that the author did not send UMI a complete manuscript and there are missing pages, these will be noted. Also, if unauthorized copyright material had to be removed, a note will indicate the deletion.

Oversize materials (e.g., maps, drawings, charts) are reproduced by sectioning the original, beginning at the upper left-hand corner and continuing from left to right in equal sections with small overlaps. Each original is also photographed in one exposure and is included in reduced form at the back of the book.

Photographs included in the original manuscript have been reproduced xerographically in this copy. Higher quality $6 " \mathrm{x}$ 9" black and white photographic prints are available for any photographs or illustrations appearing in this copy for an additional charge. Contact UMI directly to order.

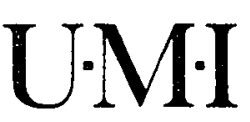

University Microfilms International

A Bell \& Howell Information Company

300 North Zeeb Road. Ann Arbor. MI 48106-1346 USA

$313 / 761-4700 \quad 800 / 521-0600$ 

Order Number 1359044

The relationship between mild to moderate hearing loss and academic achievement in reading in elementary school children

O'Hara, Maureen Patricia, M.S.

San Jose State University, 1994

Copyright (C)1994 by O'Hara, Maureen Patricia. All righte regerved.

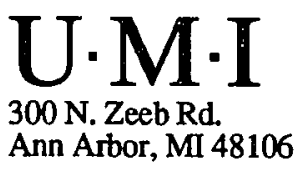



The Relationship Between Mild to Moderate Hearing Loss and Academic Achievement in Reading in Elementary School Children

\author{
A Thesis \\ Presented to \\ The Faculty of the School of Nursing \\ San Jose State University \\ In Partial Fulfillment \\ of the Requirements for the Degree \\ Master of Science
}

By

Maureen P. O'Hara

August, 1994 
Q 1994

Maureen P. O'Hara

ALL RIGHTS RESERVED 
APPROVED BY THE DEPARTMENT OF NURSING

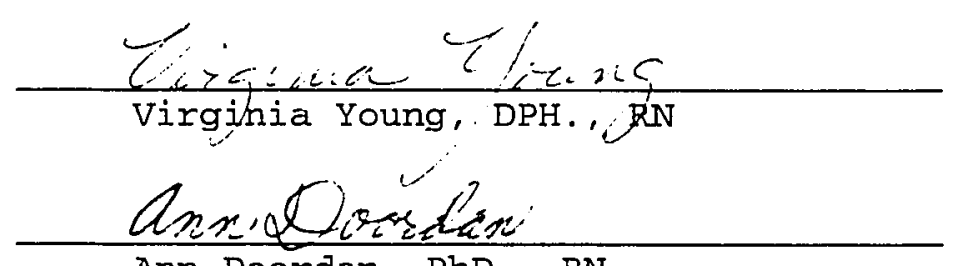
Ann Doordan, PhD., RN

Airabsth Homan M.A.CCC-Sip Elizabeth Homan, M.A., CCC-SLP

APPROVED FOR THE UNIVERSITY

In. Sou Steuranturathi 


\begin{abstract}
THE RELATIONSHIP BETWEEN MILD TO MODERATE HEARING LOSS AND ACADEMIC ACHIEVEMENT IN READING IN ELEMENTARY SCHOOL CHILDREN by Maureen P. O'Hara

This study examined the difference in academic achievement in reading scores between children who passed or failed hearing screening tests, $\mathbb{N}=52$. Retrospective data were collected from existing health and cumulative education records for 3 consecutive school years. Second and fifth grade children who failed the hearing screening ( $\mathbf{n}=26)$ were matched with a comparison group of children who passed the hearing screening $(n=26)$ by school year, gender, grade, teacher, and age. The $t$ test was used to statistically analyze the data. The group of children who failed the hearing screening did show lower grades in reading compared to the group of children who passed, but statistical significance was not demonstrated. Recommendations for school nurses' interventions and further research are discussed.
\end{abstract}




\section{ACKNOWLEDGMENTS}

To my co-workers for all their support and help, the Los Gatos Union School District for accessibility, to my readers, Virginia Young, Ann Doordan, and Elizabeth Homan, for their time and encouragement to completion, and,

most importantly to my mom, Mildred orHara for her unconditional support, and to my daughter, Cailtin O'Hara Mottet, who worked through the classes with me. 
Table of Contents

Page

LIST OF TABLES $\ldots \ldots \ldots \ldots \ldots \ldots \ldots \ldots \ldots \ldots \ldots \ldots \ldots \ldots \ldots \ldots \ldots$

Chapter

1. INTRODUCTION $\ldots \ldots \ldots \ldots \ldots \ldots \ldots \ldots \ldots \ldots \ldots \ldots \ldots \ldots \ldots$

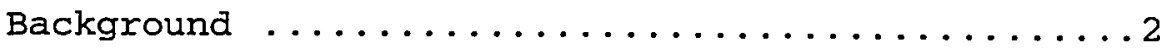

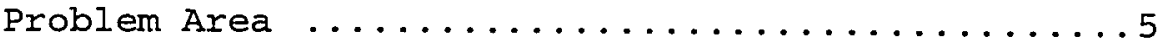

Purpose of study $\ldots \ldots \ldots \ldots \ldots \ldots \ldots \ldots \ldots$

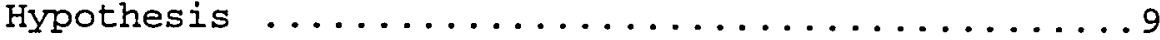

Definition of Terms $\ldots \ldots \ldots \ldots \ldots \ldots \ldots$

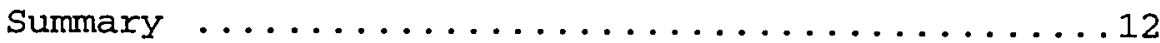

2. CONCEPTUAL FRAMEWORK AND REVIEW

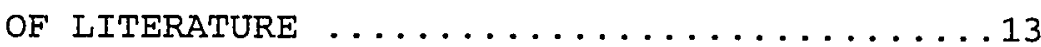

Conceptual Framework .................13

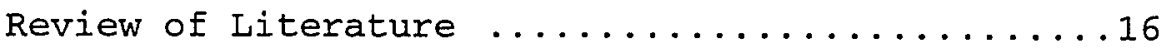

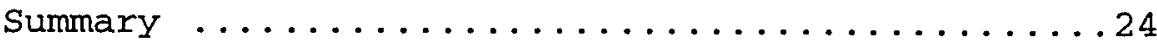

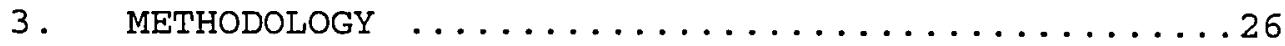

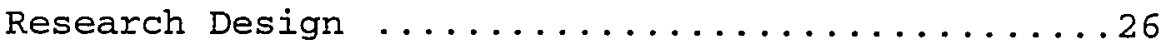

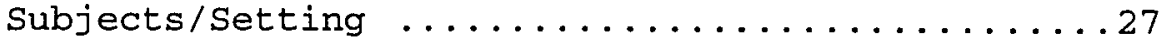

Human Subjects Approval $\ldots \ldots \ldots \ldots \ldots \ldots \ldots \ldots$

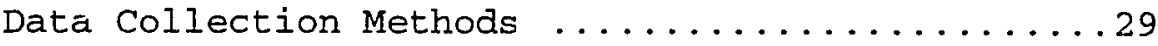

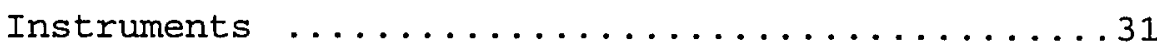


Page

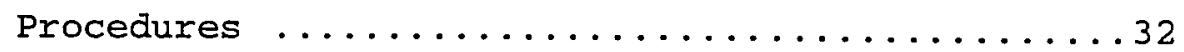

Data Analysis ....................... 34

4. FINDINGS AND INTERPRETATION $\ldots \ldots \ldots \ldots \ldots \ldots \ldots$

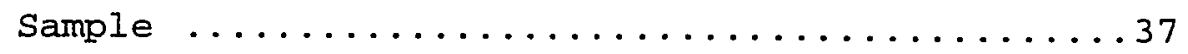

Results and Data Analysis .....................

Testing of the Hypothesis $\ldots \ldots \ldots \ldots \ldots \ldots 1$

5. DISCUSSION $\ldots \ldots \ldots \ldots \ldots \ldots \ldots \ldots \ldots \ldots \ldots \ldots \ldots \ldots \ldots \ldots \ldots$

Summary of study $\ldots \ldots \ldots \ldots \ldots \ldots \ldots \ldots \ldots \ldots \ldots \ldots$

Conclusions $\ldots \ldots \ldots \ldots \ldots \ldots \ldots \ldots \ldots \ldots \ldots \ldots \ldots \ldots \ldots \ldots \ldots$

Scope and Limitations $\ldots \ldots \ldots \ldots \ldots \ldots \ldots \ldots \ldots \ldots \ldots \ldots \ldots$

Recommendations for Further Research .......47

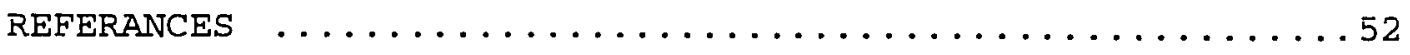

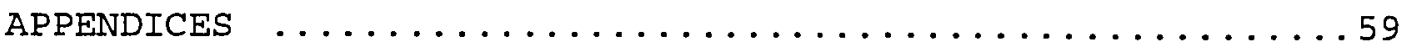

A. Approval by Human Subjects Institutional

Review Board ...............61

B. Approval from school district ..........63

C. Data Collection From A: For Review of Existing Records by Classroom ........65

D. Collection Form B: Code Numbers for Classrooms $\ldots \ldots \ldots \ldots \ldots \ldots \ldots \ldots \ldots \ldots \ldots \ldots \ldots \ldots \ldots$

E. Collection Form C: For review of Existing Health and Cumulative Folders ........69 


\section{I.TST. OF TABLES}

Table

Page

1. Distribution of Sample by Grade Level and

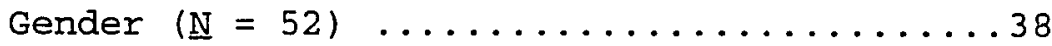

2. Distribution of Sample Failing Hearing

Screening Results According to Reading

Grades ....................40 


\section{Chapter 1}

INTRODUCTION

Hearing screening is a vital part of school health evaluations and is currently a mandated activity in public schools in 618 of the states in the United States (zanga \& Oda, 1987). In California, it is mandated that all kindergartners, or 1st graders, $2 \mathrm{nd}, 5 \mathrm{th}, 8 \mathrm{th}$, and $10 \mathrm{th}$, or 11th graders, as well as those children in special Day classes be screened. Children are screened bilaterally at frequencies of $1,000,2,000$, and 4,000 Hertz (Hz) with an intensity set at 25 decibels (OB) (Destephano-Lewis \& Thomson, 1986). Those children who do not pass the initial screening are immediately given a threshold hearing test. A medical or audiological referral is made for those children who fail the threshold test. The school nurse administers another threshold hearing test 2 weeks following the referral to reassess those childrens' hearing. Pure tone acoustic audiometry is the method of testing.

It is estimated that of the 49 million children in the school population, between 5\% (Bess, 1992; Dworken, 1985) and $20 \%$ (Anderson, 1987; Flexer, Wray, \& Ireland, 1989) have hearing loss in at least one ear. The loss may be mild to moderate as well as temporary, transitory, progressive, or permanent. Blair, Peterson, and Viehweg (1985) contend that even mildly impaired children exhibit delays in academic and 
language development. Menyuk (1980) adds that these delays can have far reaching effects not only academically, but socially.

It is accepted that severe hearing loss negatively effects language and cognitive development (Skinner, 1978). Effects of mild to moderate hearing loss, however, are not as clearly defined. A mild to moderate, permanent, or fluctuating hearing loss may not be recognized or diagnosed from standard hearing screenings with a $25 \mathrm{~dB}$ hearing threshold level screening criteria. Behaviorally, children may respond inconsistently presenting a confusing picture to parents, health care providers, or school staff. These children may be mislabeled as slow, inattentive, a behavior problem, lazy, stupid, or feigning a hearing loss (Skinner, 1978). These children are not overtly handicapped or easily recognizable, not a focus of special education services or personnel, and not "represented by a national organization of parents or educators who seek to inform the public of specific problems faced by hard-of-hearing children" (p. 43). According to Bess (1985), these children are the "invisible children" in the school system.

Background

Middle ear disease, medically labeled as otitis media $(\mathrm{OM})$, is one of the more prevalent heat $1 \mathrm{~h}$ problems in 
children. In the acute state, the disease is usually charactyerized by the presence of fluid in the middle ear and outward signs of illness. Complications of OM include hardening of the tympanic membrane, perforation of the tympanic membrane, labyrinthitis, mastoiditis, and possible facial paralysis (Stata, 1988). Most children have impaired hearing when this fluid is present. Even following antibiotic therapy, fluid can remain in the middle ear for as long as 3 months causing a more chronic than acute condition (Bluestone, et al., 1983). Chronic OM is a leading cause of conductive hearing loss in children (Bess \& McConnell, 1981; Kavanaugh, 1986; Roeser \& Downs, 1981).

Kavanaugh (1986) contends that OM is most frequent during the first 3 years of life with peak incidences occurring between 6 and 18 months of age. Children who have early onset of OM are more likely to have severe and recurrent infections. Children age 7 years and over are less apt to have OM.

Otitis media affects up to 208 of the school-aged population making the hearing impaired the largest group of handicapped school-aged children (Flexer et al., 1989; Lerner, 1988). OM is an acute and/or chronic condition and is frequently accompanied by hearing loss of varying degrees. Because of this loss, 1istening, hearing and understanding 
can be very difficult, frustrating, and confusing for children. The same sound may be heard clearly one day, muffled the next, completely distorted at another time or even missed entirely. The sibilant speech sounds in the higher frequencies, such as the "f", "sh", "s", "th", "ch", and the possessive and plural sounds as well as those in the lower frequencies, such as the "nm", "ngl" "j", and "b" sounds are most vulnerable for mishearing and misinterpreting (Dobie \& Berlin, 1979). Subtle patterns of stress in speech or speech inflections, which can convey additional information and emotional meaning about the speaker or content material, may also be missed or misinterpreted (Skinner, 1978).

Flexer et al. (1989) contend that children spend at least $45 \%$ of their school day involved in listening activities. Background classroom noise and distracting situations can make hearing, listening, and attending difficult for all children. Ordinary background sounds such as those sounds which come from outside activities, others talking, and air conditioning or heating systems in the classroom cause extraneous noise. Depending on the intensity levels, it is generally not difficult for children with normal hearing to fill in missed acoustical cues. For children with a hearing loss, a lack of consistent speech and 
language patterns make these tasks more difficult. These children may not be able to correctly fill in missed details or sounds (Skinner, 1978), or may not be aware that sounds, such as classroom instructions and directions, had been issued. Anderson (1987) states that the educational significance of childrens' hearing difficulties is determined by the degree of hearing loss, language development, academic progress, listening skills, and attending ability. Ventry (1980) adds that if a link between conductive hearing impairment and learning, listening and auditory dysfunction can be demonstrated, it could have profoundly positive educational, medical, and social implications for children. Problem Area

Critical periods of speech and language development occur prior to age 3 years which is when children are also most susceptible to chronic midale ear disease. Roberts et al. (1986) suggest an association between early OM and deficits in language, cognition, and academic skills due to hearing fluctuations and inconsistent input of information upon which speech and language patterns and skills are learned.

Zinkus and Gottlieb (1980), contend that with transient or permanent hearing loss, auditory processing skills involving the identification, interpretation, and organization of auditory sensory data are disrupted. Since 
auditory processing skills are fundamental to language acquisition, disruption of skills such as auditory sequential memory, sound blending, and auditory discrimination often impair academic development, especially in the area of reading. Stata (1988) adds that reading skills which involve linking letters and sounds may be affected by $O M$ with its subsequent hearing loss. If sounds are not received clearly and consistently, it is difficult to express them back clearly and consistently.

Roberts et al. (1989) also reported that varying mild to moderate hearing loss from OM, especially during the early years of language acquisition, may be responsible for later developmental difficulties. Auditory signals may be missed, received inconsistently, partially, or in a confused manner, all of which have potential adverse consequences.

One such consequence is possible interference with language development and verbal skills which is a prerequisite for understanding vital concepts in school. This impairment may reduce levels of academic achievement especially in areas such as reading and math in which new concepts are constantly introduced. A second consequence is that there may be difficulty with children attending to auditory stimuli, as in being attentive and following directions. This behavior may be interpreted as 
distractibility and inability or lack of desire, to be attentive or to work independently.

Bloom (1988) states, "reading is the key to school success during the elementary school years, as well as in later years" (p. 15). He further states that achievement at one grade level is highly predictive of achievement at subsequent grade levels. If children learn well and enjoy elementary school, they are much more likely to enjoy and thrive in their later school years. Without classroom and home intervention, it is likely that those children who have difficulty in elementary school will continue to have difficulty in later school years which can affect their behavior, self-concept, aspirations for, and dedication to, further education. By identifying children at risk for reading, future academic success can be fostered. Since the elementary school years are critical periods of academic development and growth, an early positive attitude toward reading for not only school work but pleasure should be fostered by teachers. In an elementary school survey, Heathington and Alexander (1984) found that although teachers rate attitude toward reading as more important than phonics or silent and oral reading, classroom time was utilized more in the development of those skills. The importance of these skills is more evident in midale school, high school, and college where reading is an integral part of 
studying. Large amounts of information must be read, understood, processed and remembered. Learning these skills in the lower grades benefits the older student later with reading and absorbing information (Salinger, 1985).

Purpose of study

Mild to moderate hearing losses have been found to affect speech and language development, cognitive learning and social development. These hearing losses, however, may be undetected in children who are asymptomatic of acute infections. It is mandated in California (Department of Health Services, 1990) that all children in specific grade levels be screened for hearing loss using pure tone audiometry under the direction of an audiologist or a school nurse who is a certified audiometrist. Those children who fail the initial screening are immediately given a pure tone threshold hearing test to more accurately determine hearing levels. Students failing the threshold test are referred for further medical evaluation and treatment. Two weeks after referral, the school nurse administers another pure tone threshold hearing test to reassess these students' hearing. The purpose of this descriptive study was to determine if there are differences in academic achievement in reading in elementary school children according to hearing screening results. One group consisted of those children who were identified, by failing the screening and the threshold test, 
as having mild to moderate hearing losses at the time of the screening. The second group consisted of children who passed hearing screening and were not identified as having mild to moderate hearing losses at the time of the screening.

Hypotheses

The research question for this study stated: Is there a difference in reading scores for elementary school-aged children who have mild to moderate hearing loss when compared to children with normal hearing? The research hypothesis examined was: Children with a mild to moderate hearing loss will have lower reading scores than children in a matched comparison group who do not have a hearing loss.

\section{Definition of Terms}

The following terms are defined for the purpose of this study:

1. Academic achievement in reading is identified by a cumulative academic grade given to a student by the teacher. For second grade students the possible academic grades are: outstanding (O), satisfactory $\left(S^{+}\right),(S),\left(S^{-}\right)$, or needs improvement (I). For fifth grade students, the possible academic letter grades are: A, B, C, D, or F. The academic letter grade was used without plus or minus signs.

2. California Assessment Program (CAP) scores are the scores achieved by the children in the school district in reading, written expression, and math which are reported as 
percentiles when compared to the scores of other children in other schools in the state.

3. Conductive hearing loss is defined as hearing loss originating in the outer or middle ear and not involving the inner ear or auditory nerve. It is the most common kind of hearing loss found in school-aged children and is usually the result of otitis media. It may be temporary, transitory, progressive or permanent (Roeser \& Downs, 1981).

4. Decibel $(A B)$ denotes the intensity, or power, of sound based on a logarithmic scale such that a sound level of $10 \mathrm{~dB}$ has 10 times more intensity than a sound of zero $d B$. There is a sound produced by the audiometer at zero $d B$, therefore, zero $\mathrm{AB}$ can be perceived by the human ear (Berg, 1987).

5. $\mathrm{dBHL}$ is the reference for the decibel (dB) hearing (H) level (L) used to express deviation from normal hearing sensitivity. The threshold sensitivity of the normal ear at each frequency is described as zero dBHL. A sound of $25 \mathrm{dBHL}$ indicates that sound perception is $25 \mathrm{~dB}$ above the normal hearing threshold for that frequency (Roeser \& Downs, 1981).

6. Frequency is the pitch of sound presented during puretone audiometry. It is described in Hertz ( $\mathrm{Hz})$. Hearing is screened at $1,000,2,000$, and $4,000 \mathrm{~Hz}$. (Roeser \& Downs, 1981). 
7. Mild hearing loss is defined as a hearing loss of 26-40 dBHL (Bess \& McConne11, 1981).

8. Moderate hearing loss is defined as a hearing loss of 41-55 dBHL (Bess \& MCConnel1, 1981).

9. Otitis media (OM) is the presence of inflammation in the middle ear cavity (Kavanaugh, 1986). Suppurative otitis media is an acute inflammation characterized by fever, pain, redness of the ear drum, and a significant conductive hearing loss. It responds readily to antibiotic therapy (Roeser \& Downs, 1981). Chronic otitis media is the presence of infection with purulent arainage which persists beyond the time usually associated with acute otitis media. There may be pain, and hearing loss can be quite severe (Kavanaugh, 1986). Fluid in the midale ear space without obvious infection is referred to as serous otitis media. Otitis media can be purulent in nature, which can be treated with antibiotics, or sterile in nature, which can not be treated with antibiotics. Otitis media can also result from allergies with subsequent hearing loss (Kavanaugh, 1986).

10. Puretone Acoustic Audiometry tests hearing with a series of pure tones which are presented to a listener at different frequencies and intensities through a set of head phones. The listener responds in a predefined manner once a sound is perceived (Roeser \& Downs, 1981). 
Summary

Otitis media is a common childhood disease which can result in permanent, temporary, fluctuating or transient hearing loss. A hearing loss during the critical period of speech and language development during the first $41 / 2$ to 5 years of life can result in language, academic, and social development delays. If a hearing loss is asymptomatic or mildly symptomatic and undetected, children may appear inattentive, slow, or be seen as having a behavior problem in school.

As many as $20 \%$ of elementary aged children have hearing levels outside the normal range (Anderson, 1987; Flexer et al., 1989). It is important to understand the relationship between hearing loss and academic achievement. Classroom teachers, support personnel, and parents need to be aware of possible academic implications for children with hearing loss.

Reading is crucial for academic success. Achievement at one grade level is highly predictive of achievement at subsequent grade levels. If children learn well and enjoy learning in the elementary school, they are more likely to learn well and enjoy learning in later school years and in adulthood. 


\section{Chapter 2}

CONCEPTUAL FRAMEWORK AND REVIEW OF LITERATURE

This chapter presents the conceptual framework and review of literature for this study. The conceptual framework is based on Piaget's learning theory and is presented first. A review of the literature follows. Conceptual Framework

The conceptual franework for this study is based on Jean Piaget's theory of cognitive or intellectual development (Pulaski, 1980). Piaget teaches that people construct their knowledge (intelligence) from their experiences of acting upon, interacting with, and adapting to persons and things in the enviromment. These constructs of knowledge are identified as schemata which are organized, internalized, and act as a foundation for further cognitive and intellectual development. The learning/adaptive process involves a balance between assimilation and accommodation.

Assimilation is the process of taking new information into an existing schemata, adding, and fitting as appropriate and possible. When new bits of information cannot be assimilated into preconceived ideas, individuals must accommodate or rearrange that material either by reorganizing existing ideas or by forming a new one (Johnston \& Johnston, 1984). 
Piaget has defined four distinct stages of intellectual development: sensorimotor, preoperational, concrete operational, and formal operational (Pulaski, 1980). The sensorimotor and preoperational are of primary importance in dealing with preschool language learners. Language modeling, questioning and feedback activities are all designed to encourage children to construct knowledge and language.

The sensorimotor schemata stage occurs between the ages of zero and 18-24 months (Johnston \& Johnston, 1984). By tasting, manipulating, and throwing things, infants interact with objects in the environment. They begin to organize themselves in time and space, thereby laying the basis for the language concepts such as "in," "on," "under," and "over." The concepts of causality and intentionality are being developed, which generate thoughts such as "because," "before," and "until." If sensorimotor knowledge does not emerge, there is a concern that language will not develop normally. Piaget contends that the development of language is based on the prior development of sensorimotor operations (Johnston \& Johnston, 1984).

A transitional phase between the egocentric sensorimotor (Pulaski, 1980) and preoperational period is a prerequisite for language development (Johnston \& Johnston, 1984). 
Although the young children have been communicating with important people by the use of gestures and utterances up to this point, language is refined during the preoperational period.

The preoperational period extends from 18-24 months until 7 years of age (Pulaski, 1980). During this stage knowledge acquired during the sensorimotor stage is built upon and expanded. Mental operations and thinking are more evident.

The concrete operational period covers the ages between 7 and 11 or 12 years of age (Johnston \& Johnston, 1984). During this period, children are able to perform more complex mental operations and categorizations such as logical reasoning, and organizing thoughts into coherent patterns to arrange them in a heirachy of sequential relationships (Pulaski, 1980). During these elementary years, basic concepts and processes in reading, writing, science, arithmetic, social science and interpersonal relationships are established.

The formal operational period lasts from ages 11-12 years of age through adulthood (Johnston \& Johnston, 1984). Concepts that have been established are developed to a more advanced level. The ability to deal with advanced conceptual areas, abstract meanings, and hypothetical thought, is 
acquired and refined. Language is an integral part of understanding and communicating these thoughts. As children progress through these four hierarchical stages, the building blocks in each period are developed, added to and refined. If growth and development, especially in the sensorimotor and preoperational periods has not occurred, the normal development of language is unlikely.

Johnston and Johnston (1984) state that children who have serous otitis media (OM) are at high risk for hearing related language and learning problems. Children with treated or untreated hearing disorders or listening difficulties are at high risk for language or learning disorders, even if there has been a correction of hearing, through hearing aids or pressure equalizing tubes. Interruptions in language reception affects learning in the classroom. Although actual hearing loss may be mild to moderate, hearing loss during prime language learning years can cause catastrophic problems. Gaps in language reception from distorted auditory signals create a faulty base upon which to build subsequent language development.

\section{Review of Literature}

Many studies have investigated the effects of hearing loss and academic achievement with most addressing the effects from otitis media. Because $O M$ is the most comon 
cause of hearing loss in children (Kavanaugh, 1986), these studies are included in the literature review. Kaplan, Fleshman, Bender, Baun and Clark (1973) conaucted a 10 year cohort study of 489 Alaskan Eskimo children. The study included children in 27 villages in Southwest Alaska. The childrens' medical records were reviewed and histories of OM were obtained through medical records and parental interviews. Otoscopic examinations were performed by a physician. Audiologists tested the children in quiet rooms in the school or community building using recently calibrated portable audiometers. Psychological testing for intellectual potential and current functioning ability was completed by two psychologists who were specifically trained for and experienced in testing native children. Achievement tests results were obtained from school records.

The study concluded that there is a statistically significant reduction in verbal skills and school achievement for children with a history of early OM with mild hearing loss compared to nonaffected children (Kaplan et al., 1973). It was also found that children with a history of early oM with normal hearing at school screening still showed lower verbal and academic scores than nonaffected peers, and the gap tended to widen as grade levels progressed. This widening gap is an important consideration in educational 
planning as the affected children may need special assistance in the classroom to achieve success.

Marion Downs, a noted authority in pediatric audiology, (Bluestone et al., 1983) stated that approximately 30 studies involving 3,500 children, consistently showed that early fluctuating hearing losses are associated with decreased language, cognitive skills, and school achievement. Blair et al. (1985) conducted a study with 24 mildly hearing impaired first through fourth grade students and 24 normal hearing first through fourth grade students selected from a large Utah school district. Their school achievement scores on a standardized test were compared in an attempt to clearly define the relationship between mild hearing loss and academic performance. The researchers also questioned whether a delay increases, decreases, or remains constant, as the grade levels progress.

The results of this study indicated that normal hearing students scored better than their mildly hearing impaired peers, especially in the areas of vocabulary, reading comprehension, and language. The authors further stated that the negative effect of hearing loss on general academic ability was progressive and increased as the students advanced in grade levels.

Sak and Ruben (1981) used a "sibling control paradigm" to examine the relationship between hearing loss from OM in 
the preschool years and subsequent cognitive and academic performance. One child of each of the 18 pairs of siblings had a documented history of recurrent OM with effusion during preschool years while the other child did not. The findings showed that siblings with OM were significantly depressed in verbal functioning, auditory decoding, and spelling skills when compared with their sibling controls. Perhaps utilizing compensatory strategies for their auditory deficits, the siblings with OM showed significant strengths in visual sequential memory when compared to normal hearing sibling controls.

In an effort to examine the effects of chronic om during the first 3 years of life on developing auditory processing skills, Zinkus and Gottlieb (1980) compared two groups of 30 children each in the areas of language development, intelligence, auditory processing skills, and academic abilities. One group had a history of chronic om during the first 3 years of life whereas the other did not. Both groups had a history of auditory processing difficulties. The findings indicated that those children with a history of chronic OM were slower in developing word combinations, had depressed verbal intelligence scores, showed pervasive auditory processing deficits, and were significantly poorer in reading. The significance of the poorer reading scores is 
important because of the relationship between reading and academic success. Arithmetic calculation was least affected. Two research psychologists investigated the relationship between minimal hearing loss (15-30 dB) and academic and intellectual functioning with a group of 552 fourth, fifth and sixth grade children (Burgener \& Mouw, 1982). Audiometric, academic and intellectual data were gathered. Findings showed that even hearing thresholds of $15 \mathrm{dBHL}$ correlated with lower academic and intellectual functioning. The researchers concluded that normal hearing does not predict good academic performance, but minimal hearing loss is related to poor performance. Bess and McConnell (1981) concur with these findings stating that hearing loss in the vicinity of 15-20 dBHL can produce handicapping effects. They suggest a need to reexamine the present system classifying normal hearing and degrees of hearing loss which extends normal hearing to $25 \mathrm{dBHL}$.

Some studies of early OM show little or no correlation with language or cognitive development. Brandes and Ehinger (1981) studied the effects of early middle ear pathology on academic achievement. The control group consisted of 15 normal hearing children who passed the previous year's hearing screening and had no significant history of ear infections, allergies or sinus problems. The 
conductive hearing loss (CL) group consisted of 15 milaly to moderately hearing impaired children with a positive history of midale ear pathology. The investigators stated that although chronic recurrent middle ear problems may produce secondary effects beyond temporary conductive hearing loss, their results indicated that even though the children with hearing loss did not do as well as their peers, the difference was not significant. The results did indicate, however, that the CL group did perform significantly lower than the control group in discriminating auditory stimuli in the presence of background noise. The authors observed that those children with hearing loss were receiving special support services such as speech and language therapy, and stated that there may be a need for children with histories of early middle ear pathology to receive special assistance to assure success in school.

In reviewing the evidence implicating conductive hearing loss as the cause of learning disabilities, language dysfunction, and auditory problems, ventry (1980) strongly criticized published research. Ventry states:

that the relationship has been poorly documented, that methodological flows in the published research have contaiminated the data and confounded the reported results, and that there is a continuing need, as so many 
investigators have emphasized, for ongoing research in this area (p. 150).

Ventry supports his original statement 3 years later stating that although additional studies have been published, there has been no causal link established between early recurrent middle ear pathology and language delay or learning problems (Bluestone et al., 1983).

Roberts et al. (1986) state that a meaningful relationship between hearing loss and developmental difficulties in childhood remains controversial. In this longitudinal study a group of 61 socio-economically disadvantaged children who attended a research day care program were medically followed from infancy until the age of 3 years for OM. Standardized intelligence and academic tests were administered to the children when they were $31 / 2$ to 6 years of age. All children were screened in kindergarten and none were found to have a hearing loss. This study found no evidence of associations between measures of early childhood OM and measures of verbal or academic functioning.

Language performance was evaluated in a study of 167 healthy Apache Native-American chilaren, age 6 to 8 years who had been medically followed since birth (Fischler, Todd \& Feldman, 1985). Results indicated that some children had medical histories of frequent OM, while others had histories of infrequent bouts of OM. All children received pneumatic 
otoscopy, tympanometry, pure tone audiometry and a battery of language tests. No statistically or clinically significant differences were found in either group. In this study and in the study by Roberts et al. (1986), the children were medically followed from infancy, prompt intervention and treatment may have prevented significant hearing loss.

Experts in pediatrics, infections diseases, laryngology, audiology, speech, Iinguistics and pathology attended a workshop to examine the effects OM has on children (B1uestone et a1., 1983). They concluded that om was one of the most common childhood diseases, and there was a concern about frequency, morbidity, complications and sequelae as well as variable hearing loss resulting from OM. There was a lack of consensus about what specific hearing thresholds constitute clinically significant hearing 1oss. It was concluded that:

temporary developmental impairments result from hearing loss of moderate or severe degree that is long-standing and unremitting, but no convincing evidence exists at present to relate developmental impairments to single or multiple episodes of short-term hearing loss or to mild hearing loss irrespective of duration (p. 649). Ventry (1980) has strongly criticized the methodological and documentation problems evident in published research on hearing loss related to language and 
learning impairments. He also stated that if a positive correlation between $O M$ and learning disorders can be shown, changes could be made to prevent and ireat learning disorders. At the National Institute of Child Health and Human Development meeting held in Bethesda, $M D$ in 1985, it was concluded that growing evidence indicates that a significant relationship does exist between conductive hearing loss resulting from recurring $O M$ and subsequent language and academic difficulties (Eimas \& Kavanaugh, 1986). Those who attended agreed that intervention programs must be developed and implemented until preventative measures are available. It was recommended that all infants and children, especially those at risk, be examined and treated for OM. The children should be followed for hearing loss, with the intervention of speech and language therapy if required (Eimas \& Kavanaugh, 1986).

\section{Summary}

Jean Piaget's theory of cognitive development outlines four separate developmental stages of growth for children. During each necessary stage, children construct knowledge from their experiences through assimilation and accommodation. The sensorimotor and preoperational stages are of critical importance in learning language. Because learning is hierarchical in nature, depressed or fluctuating hearing can cause significant disruption in the patterns of 
language children are supposed to learn. The disruption can produce developmental difficulties.

Although many studies have been conducted to determine if there is a relationship between hearing loss and language and cognitive skills, no cause and effect relationship has been established. The issue remains controversial. Otitis media is one of the more prevalent health problems and the leading cause of conductive hearing loss in children. Children who have histories of OM should be followed medically for intervention and treatment. Those children may need support services academically to assure school success. 


\section{Chapter 3}

METHODOLOGY

The purpose of this study was to determine if there is a relationship between mild to moderate hearing loss and academic achievement in reading. Two groups of children were studied. One group consisted of children who failed the hearing screening conducted at school. The second group consisted of children who had passed the hearing screening. The research question was: Is there a difference in reading scores for elementary school aged children who have mild to moderate hearing loss compared to children with normal hearing? The research hypothesis examined was that children with a mild to moderate hearing loss will have lower reading scores than children in a matched comparison group who do not have a hearing loss.

\section{Research Design}

This study used a retrospective, cross-sectional, descriptive design. School health records for all second and fifth grade children in one school district were examined for pure tone audiometric screening results for the 1990-1991, 1991-1992, and 1992-1993 school years. All second and fifth grade children who failed the hearing screening and who had an audiogram which showed a mild to moderate hearing loss 
during those 3 years were included in the study. Children with a known severe hearing loss or those children who wore hearing aids were not included in the study.

A comparison group of children who did not fail the hearing screening was selected by reviewing the same school health records. The children were individually matched to children who failed the hearing screening by school year, gender, grade, teacher, and age. Children in the group who did not fail hearing screening were matched within 2 months of age to those children who did fail hearing screening. None of the children in either group was receiving special education assistance in reading outside the classroom. Subjects/setting

The records included in this study were for children who lived in a community of 27,000 people located in the south San Francisco bay area in northern California. The school district was composed of 5 elementary schools, 1 middle school, and I high school, with a total student population of 2,250 children. The average class size was 26 children per teacher. The California Assessment Program (CAP) scores for this school district rated it to be in the 96 th percentile in reading scores compared to other south San Francisco bay area elementary and unified school districts (Bernardo, 1993). In this community, the average income per household in 1991 was $\$ 63,500$ and the average cost for a single family home was 
$\$ 517,155$. The community supports 2 general hospitals and there are numerous physicians' offices providing accessible health care. Eighty-three percent of the population was white, 9.08 Asian, 4.38 Hispanic, 1.48 Native-American, 1.28 African American, and 0.48 Filipino (Bernardo, 1993). The number of children at the elementary and middle schools who receive free or reduced lunch, which is an indicator of a low income household, was 135 , or 68 , of the children in the school district.

\section{Human Subjects Approval}

Initial approval for this research project was obtained from the school district office in January 1993 (Appendix A). The director of Special Education/Projects gave written approval to gather needed data. San Jose State University Human Subjects Institutional Review Board granted approval for this study in June 1993 (Appendix B). Data were gathered from the elementary and middle school records in June and July of 1993. The rights and welfare of the children were carefully protected through strictly maintained confidentiality. Forms which indicated the child's assigned identification number were kept locked and separate from other data collection tools. Records were reviewed and results recorded on forms at the school sites after school hours. Data were collected using code numbers so that the children could not be identified or linked to the data. 
Forms containing data were kept in a locked brief case. No individual written consent form was necessary since the research was done using existing data within the school district.

\section{Data Collection}

In California all kindergartners or lst graders, 2nd, 5 th, 8th, and loth or lith graders, as well as those children in Special Day classes, are to be screened for hearing loss. The purpose of this hearing screening is to identify children with hearing losses which may affect their educational, emotional, social, speech and/or language development. Hearing screening is mandated in section 2951, of the California Administrative Code, Title 17 (1986). It states that the method of testing consists of pure tone acoustic audiometry conducted under the direction of an audiologist or a school nurse who is a certified audiometrist. A pure tone screening or sweep-check test is given first in the right ear at frequencies of $1,000,2,000$ and $4,000 \mathrm{~Hz}$, then in the left ear at $4,000,2,000$ then $1,000 \mathrm{~Hz}$ at the intensity level of 25 dBHL. Failure of a child to respond to any of the required frequencies at the screening level constitutes a failure of the screening test, and that child is immediately given an individual threshold test at 500, 1,000, 2,000, and 4,000 $\mathrm{Hz}$ (Department of Health Services, 1990). A second threshold test is given within 2 to 4 weeks following the 
first. A threshold test determines more precisely at what intensity the child hears the tone at the different frequencies. All children with hearing levels of $30 \mathrm{dBHL}$ or poorer for two or more frequencies, or 40 dBHL or poorer at any one frequency, fail the hearing screening and are referred for medical/audiological follow-up (Department of Health Services, 1990).

In this study most of the initial hearing screenings and threshold tests were performed by an audiometrist who contracted with the school district to provide that service. The group screenings were held in early to mid september 1991, 1992, and 1993. Testing, using a Beltone puretone portable audiometer, was conducted in a sound insulated van at each of the 4 school sites on 3 successive days. Instructions were given before and during testing, and the children practiced responding as instructed to the sounds presented. Follow up audiometric threshold testing for children with hearing failures and for those children who were absent during the initial group screening were completed within 1 month of the group screening by a school nurse who is a certified audiometrist.

The follow up individual tests were done by 2 different nurses using recently calibrated, portable audiometers. Tests were performed in a quiet room at each of the 4 different school sites. Children who were referred 
for medical or audiological follow up were the subjects in this study. No child with a known severe or profound hearing loss was used as a subject in this study.

Instruments

Three data collection forms were developed and utilized by the researcher to gather retrospective, cross-sectional data for the 1990-1991, 1991-1992, and 1992-1993 school years. They were identified as Form A, Form B, and Form C. Form A (Appendix C) identified all children involved in the study $(\mathbb{N}=52)$. It was used to assign a subject identification number and to record the school code number. Form B (Appendix D) was used to assign a different identification number to each second and fifth grade teacher, and thus his or her classroom, at each of the four elementary schools for each school year involved in the study. For example, the classroom code number 01 was assigned to Ms. X, one of the 3 second grade teachers in the school year 19901991 at school A. The number 02 was assigned to Mr. Y, also a second grade teacher at the same school during the same school year as Ms. X. This pattern was maintained until all the second and fifth grade teachers at each of the four different schools for the 3 school years involved in this study were given an individual identification number. 
Collection Form C (Appendix E) identified each child by subject number, classroom code, gender, grade level, age, hearing results, and reading grade. Twenty-six children failed the hearing test and were paired with 26 children who passed the hearing test. The children failing the hearing screening were matined by school, school year, gender, grade level, and age to those children who did not fail the screening. For example, a 9 year-old fifth grade male at a particular school during a particular school year who failed the hearing screening and received a grade of $C$ in reading would be coded as follows: $05,73,1,2,3,2,8$. The number 05 indicates the subject identification number; the number 73 indicates the classroom code; the number 1 indicates gender; the number 2 indicates grade level; the number 3 indicates age in years; the second number 2 indicates hearing screening results; the number 8 indicates reading grade.

\section{Procedures}

Health records for 1991, 1992, and 1993 were examined to locate children who failed the hearing screening. Cumulative educational records for the same years were examined by the researcher to find childrens' grades in reading. Data Collection Form A (Appendix C) was used to identify the group of children with a hearing loss and the matched control group without a hearing loss by name, school, grade, and school 
year. Each child was assigned an identification number for reference. Data Form B (Appendix D) was used to assign a different identification number to each second and fifth grade teacher and thus his or her classroom at each of the four elementary schools for each school year involved in the study. For the purpose of accurately matching those children with a hearing loss to those children without a hearing 1oss, Form B was utilized to identify the specific school, grade and teacher for each school (Appendix D). Collection Form C (Appendix E) showed the assigned subject number, classroom code, gender, grade level, age, hearing results, and letter grade indicating the child's academic achievement in reading. Reading scores were based on the curriculum and standards accepted by the specific school district. No teacher involved in the study was assigned a long-term substitute or left the school during the identified school year, therefore there was consistency in the same teacher issuing the reading grades for his or her children in school. For the purpose of data analysis the researcher arbitrarily reassigned the reading scores of the second grade children to correspond with the fifth grade childrens' reading scores as follows: 
2nd Grade

I (Improvement Needed)

S- (Satisfactory -)

S (Satisfactory)

S+ (Satisfactory +)

o (Outstanding)
5 th Grade

$\begin{array}{ll}= & F \\ = & \mathrm{D} \\ = & \mathrm{C} \\ = & \mathrm{B} \\ = & \mathrm{A}\end{array}$

\section{Data Analysis}

The purpose of this study was to explore the relationship between hearing screening results and academic success in reading in elementary school-aged children. One group consisted of those children who had identified mild to moderate hearing losses at screening. The second group consisted of those children who did not have mild to moderate hearing losses at screening and were matched to the first group. The hypothesis being tested was: children with a mild to moderate hearing loss as evidenced by a failed hearing screening and subsequent audiogram, have lower reading scores than those children in a matched comparison group who do not have a hearing loss. The null hypothesis under consideration was: there is no difference in mean reading grades of elementary school-aged children who have a mild to moderate hearing loss and those chilaren who do not have a mild to moderate hearing loss. The statistical 
procedure used to test this hypothesis was a $t$ test for 2 independent means with variances pooled. A value of $0.05(\mathbb{D}=0.05)$ was used as a measure of statistical significance (Burns \& Grove, 1987). 
Chapter 4

FINDINGS AND INTERPRETATION

This chapter discusses the findings and interpretation of the data collected. The research question for this study was: Is there a difference in reading scores for elementary school aged children who have mild to moderate hearing loss when compared to children with normal hearing? The reading achievement of 2 groups of children was compared. One group of children failed the hearing screening at school and had mild to moderate hearing loss. The second group of children passed the hearing screening. Data were collected from 1 middle school and 4 elementary schools in a community with a population of approximately 27,000 people.

This chapter describes the sample population, results, and data analysis. The 3 tables present the collected data as follows: Table 1 shows sample population by grade and gender, Table 2 shows sample distribution by hearing screening results and reading scores, and Table 3 summarizes the results of the $t$ test.

The children who were involved in this study ranged from 7 years of age to 10 years of age and were selected from the 4 elementary schools in a community with a population of 27,000 people. The total number of children enrolled in the 
4 elementary schools, 1 middle school and 1 high school totaled 2,250 children. Approximately 838 of the population was white, 108 Asian, 48 Hispanic, 18 Native-American, 18 African American, and (1용 Filipino (Bernardo, 1993). Data were analyzed statistically using a $t$ test. According to Burns and Grove (1987), a t test is one of the most common analyses used to test for significant differences between statistical measures of two samples. "The $E$ test uses the standard deviation of the sample to estimate the standard error of the sampling distribution. It is particularly useful when only small samples are available for analysis" (p. 502). Due to the small sample size and to facilitate data interpretation, the second grade chilarens' reading scores of $0, S^{+}, S, S-$ and $I$ were reassigned by the researcher to correspond with the fifth grade childrens' reading scores of $A, B, C, D$, and $F$, respectively.

\section{Sample}

The sample included a total of 52 children $(\mathbb{N}=52)$, one half ( $n=26$ ) of whom had failed the hearing screening while the other half ( $\mathrm{n}=26$ ) had passed. Thirty-four of those children were in the second grade. Eighteen children were in the fifth grade. There were almost twice as many second grade children involved in this study as fifth grade children. 
By gender, the children were close to equal in number. Of the second graders, 18 were boys and 16 were girls, 538 and 478 respectively. Of the fifth graders, 8 were boys and 10 were girls, 458 and 55\%, respectively. The combined second and fifth grade children were evenly distributed by gender with 26 girls and 26 boys involved in this study. Table 1 shows the grade level and gender distribution by number and percentage.

Table 1

Distribution of Sample by Grade Level and Gender $(\mathbb{N}=52)$

Number ( 8 )

Grade Children Girls Boys

\begin{tabular}{ccccccc}
\hline & & & & & & \\
2 & 34 & $(658)$ & 16 & $(478)$ & 18 & $(538)$ \\
5 & 18 & $(358)$ & 10 & $(558)$ & 8 & $(458)$ \\
Total & 52 & $(1008)$ & 26 & & 26 & \\
\hline
\end{tabular}

Group hearing screenings records were reviewed for September of the 1990-1991, 1991-1992, and 1992-1993 school years. Individual retests and follow-up tests with absent children were completed within a month of the group screening each year. 
Results and Data Analysis

The children ( $\mathbb{N}=52$ ) not passing and passing hearing screening were matched by school, teacher, gender, grade and age. One half of the children $(n=26)$ failed the hearing screening test while the other half $(n=26)$ passed. Children with hearing levels of $30 \mathrm{~dB}$ or greater for two or more of the three frequencies tested, or $40 \mathrm{~dB}$ or greater at any one frequency, failed the hearing screening. Children with severe or profound hearing loss were excluded from this study.

Table 2 shows those children who failed and who passed the hearing screening by reading grade. Due to the small sample, the second and fifth grade reading results were combined according to letter grade in reading. Nine children, or 35\%, who failed the hearing screening received a grade of $A$ in reading. Six children, or $23 \%$, received a grade of $B$. Eight children, or 308, received a grade of $C$. Two children, or $8 \%$, received a grade of $D$ and one, or 48 , received a grade of $F$.

of the group of children who passed the hearing screening, twelve children, or 468 , received A grades. Seven children, or $27 \%$, received a $B$ grade and seven, or $27 \%$, received a $C$ grade. None of the children who passed hearing screening received a grade of less than $c$. The mean reading grade based on the numerical value shown in table 2 (range 
5 - 1 for A - F) for children who passed hearing screening was $4.19(n=26)$, whereas the numerical value for those children who failed hearing screening was 3.77 (n $=26)$. Table 2

Distribution of Sample $(\mathbb{N}=52)$ Hearing Screening Results According to Reading Grades,

Number (\%)

\begin{tabular}{cccccr}
$\begin{array}{l}\text { Reading } \\
\text { Grade }\end{array}$ & $\begin{array}{l}\text { Numerical } \\
\text { Value }\end{array}$ & $\begin{array}{l}\text { Failed } \\
\text { Screening }\end{array}$ & \multicolumn{2}{c}{$\begin{array}{l}\text { Passed } \\
\text { Screening }\end{array}$} \\
\hline A & 5 & 9 & $(35 \%)$ & 12 & $(46 \%)$ \\
B & 4 & 6 & $(23 \%)$ & 7 & $(27 \%)$ \\
C & 3 & 8 & $(30 \%)$ & 7 & $(27 \%)$ \\
D & 2 & 2 & $(8 \%)$ & 0 & $(0 \%)$ \\
F & 1 & 1 & $(4 \%)$ & 0 & $(0 \%)$ \\
Total & & 26 & $(100 \%)$ & 26 & $(100 \%)$
\end{tabular}

Forty-six percent of the children who passed hearing screening received a letter grade of $\mathrm{A}$ in reading, whereas $35 \%$ of the children who failed the hearing screening received a letter grade of $A$ in reading. No children who passed the hearing screening (100\%) received a letter grade of $D$ or $F$, whereas $12 \%$ of the children who failed the hearing screening received a letter grade of $D$ or $F$. 
Testing of the Hypothesis

The $t$ test was used to analyze data and test the hypothesis that elementary aged children with mild to moderate hearing loss have lower reading scores than elementary aged children without a mild to moderate hearing 1oss. Using an alpha of 0.05 , there was no statistically significant difference in reading scores between the children with hearing loss and children without hearing loss. Therefore, hearing loss did not result in a statistically significant difference in reading scores as represented by the reading grade, although there appears to be a trend for reading grades for those children with hearing loss to be lower. 


\section{Chapter 5}

\section{DISCUSSION}

The purpose of this research study was to explore the relationship between hearing screening results and academic achievement in reading in elementary school children. One group consisted of those children who were identified as having mild to moderate hearing losses following a hearing screening and subsequent audiogram. The second group consisted of those children who passed hearing screening. This chapter presents the conclusions of this study, the scope and limitations, and recommendations for further study. Summary of the study

It is estimated that between 58 (Bess, 1992) and 208 (Anderson, 1987) of the 49 million children in the school population have hearing loss in at least one ear. The loss may be mild to moderate to profound as well as temporary, transitory, progressive, or permanent. Even mildly hearing impaired children exhibit delays in academic and language development (Blair et al., 1985) which can have far reaching effects not only academically, but socially (Menyuk, 1980). These children are labeled the "invisible children" according to Bess (1985) because there is no overt handicap and they may not be easily recognized as having hearing difficulties. Behaviorally, these children may respond to situations 
inconsistently, depending on the level of hearing loss, and may be mislabeled as slow, inattentive, a behavior problem, lazy, or stupid.

This study, using a retrospective, cross-sectional, descriptive design was conducted in a small, affluent community with a population of approximately 27,000 people located in the south San Francisco bay area in Northern California. The records used were all from the second and fifth grade children who failed hearing screening with a mild to moderate hearing loss in the school years 1990-1991, 1991-1992, and 1992-1993. These children were matched with a comparison group of children who passed hearing screening. The groups were matched by school, teacher, school year, grade, gender, and age. The hypothesis being examined was: If children have mild or moderate hearing losses in one or both ears, as evidenced by a failed hearing screening test, then grades in reading are lower than those of children who passed the hearing screening. Health and cumulative school records were reviewed in the 4 elementary schools and 1 middle school in this community for hearing results and reading grades. A t test was used for data analysis and hypotheses testing.

There was no statistically significant difference in reading scores as represented by the reading grade; however, 
there was a trend for those children with learing loss to have lower academic grades that those children without a hearing 1oss. Further supporting this trend is the fact that the only $\mathrm{D}$ and $\mathrm{F}$ grades in reading were received by those children who failed hearing screening.

conclusion

The results of this study suggest that although there was evidence for lower reading grades with children with a hearing loss, the difference in reading grades between the 2 groups was not statistically significant. Otitis media is one of the most prevalent health problems in children. Children with acute OM, which is characterized by signs of illness and fluid in the middle ear, generally show some degree of hearing impairment. Even following antibiotic therapy, fluid can remain in the midale ear causing chronic OM. Chronic OM is the leading cause of conductive hearing loss in children (Bess \& McConnel1, 1981; Kavanaugh, 1986; Roeser \& Downs, 1981). Johnson and Johnson (1984) state that children who have OM are at a high risk for hearing related language and learning problems. Although actual hearing loss may be mild to moderate, hearing loss during prime language learning years can cause catastrophic problems. Gaps in language reception from distorted auditory signals create a faulty base upon which to build subsequent language development. 
In this study the number of second grade children who failed hearing screening was almost twice as many as the number of fifth grade children who failed hearing screening, which is consistent with literature stating hearing loss is age related.

Hearing screening is not only mandated in the majority of the states in the United States, but is a vital component of school health evaluations to identify children who have a hearing impairment which might interfere with their educational growth, development, and experience. In this study, children with a mild to moderate hearing loss did have a lower mean reading grade than children who passed hearing screening. The difference was not statistically significant although reading grades were lower. These children have special learning needs in the classroom because of their hearing loss. With adequate, even aggressive, medical treatment and follow up for children who have a history of OM, the degree of hearing loss might be minimized. It is imperative for classroom teachers to identify those children who have a history of ear infections and those children who have mild to moderate hearing loss so that instructional and classroom adaptations can be made in order to meet these children's educational needs. 
Scope and Limitations

The purpose of descriptive research is to describe phenomena. This approach is used to clarify concepts and generate relationships for use in further research (Burns \& Grove, 1987). A disadvantage of a descriptive design, is that the researcher is unable to draw a cause and effect or causal linkage between the two variable to establish the results (Lo-Biondo-Wood \& Harber, 1990). Additionally, in this descriptive study, the sampling process was non-random since data were obtained from preexisting records or a convenience sample. Non-randomization decreases generalizability (Burns \& Grove, 1987).

The sample size was a limitation in this study. There were only a small number of children identified with mild to moderate hearing loss in the sample population. A matched comparison group had the same sample size. A second limitation was the ethnic make up of the sample population. Over 808 of the population was white, followed by 9.78 Asian, 4.08 Hispanic and the remaining 3.08 a mixture of American Indian, African American and Filipino. The ethnic composite of the population was not evenly distributed. The general income was more than $\$ 60,000$ per household (Bernardo, 1993) with medical care easily accessible. 
Recommendations for Further Research

As a result of this research, suggested recommendations for further research are:

1. Replication of this study using hearing screening records of children in the second grade only.

2. Replication of this study using a larger sample population.

3. Replication of this study in other school districts with different ethnic, socio-economic, and cultural distribution to determine if findings can be generalized.

4. Comparison of the second grade reading scores of girls who have mild to moderate hearing loss to the second grade reading scores of boys who have mild to moderate hearing loss.

5. Comparison studies of effectiveness of classroom adaptations made to meet the academic needs for children with mild to moderate hearing loss.

6. Research studies concerning the social and emotional impact of hearing loss on children. Recommendations for School Accommodation and Intervention

The school nurse is the first professional who intervenes with school children with hearing loss. The school nurse informs parents or guardians of their children's 
conditions, refers these children for medical or audiological care, and communicates with teachers about the difficulties children with hearing loss in their classroom might encounter. It is currently mandated in $61 \%$ of the states in the United States that hearing screenings be conducted for specified grade levels (Zanga \& Oda, 1987). Bess and McConnell (1981) outlined for each state in the United States the mandated or recommended grade levels to receive hearing screenings, the frequencies in $\mathrm{Hz}$ to be tested, and the personnel qualified to administer the hearing test. In 38 (748) of the states the mandated or recommended elementary grade levels to receive hearing screenings are: kindergarten and/or first grade and second and/or third grade. In 25 (50\%) of the states it is mandated or recommended that fifth grade children receive hearing screening. In 40 (80\%) of the states the frequencies mandated or recommended for pure tone screenings are 1000,2000 and $4000 \mathrm{~Hz}$. In 47 (948) of the states it was mandated or recommended that trained personnel, including nurses, audiologists, speech and hearing specialists, and/or trained volunteers, conduct the hearing screening tests. Thirty-eight (768) of the states mandated or recommended school nurses or public health nurses conduct the hearing screening.

Following a hearing screening, parents are notified in writing if their children failed the hearing screening and 
their children are referred for medical and/or audiological follow up. School nurses provide follow up for those children with identified hearing losses with parents, teachers and the children's physicians. Some children may have a fluctuating hearing loss, which may enable them to pass a hearing screening, but still experience difficulties in the classroom. Teachers need to be notified of this possibility, instructed to carefully observe the identified child for difficulties in the classroom, encouraged to request periodic hearing tests as indicated, and assisted in making classroom and instructional adaptations in the classroom.

school nurses can work with teachers using some of the following techniques (Davis 1989) for curriculum adaptation in the areas of audition, cognition, language, and socialization. It is the school nurse's role and responsibility to communicate with teachers and frequently reinforce possible adaptations in the classroom in the areas of audition, cognition, language and socialization so that children with mild to moderate hearing loss do not become "invisible children" and suffer academically.

In the area of difficulties with audition, school nurses can encourage the following: (a) minimization of extraneous noise by treating the room with sound absorbing materials such as acoustical tile, (b) preferential seating 
of the child near the front of the classroom where auditory instructions are given, (c) speaking directly to the child's face when giving instructions, and (d) requesting feedback and clarification from the child following verbal and written instructions (Davis, 1989). Cognitively, a child with a hearing loss learns better through senses other than auditory. Other adaptations which school nurses can suggest are: (a) the use of multiple teaching modes such as auditory, visual and kinesthetic, (b) small group instruction, (c) securing the child's attention prior to instruction giving, and (d) allowing the child additional time to process, internalize, and restate the presented thought (Berg, 1987).

School nuses can assess language skills with which the child with a hearing loss might have difficulty, including recalling names of items, word relationships such as spatial, temporal or causal, and plurals, possessives and irregular past tenses. Among the instructional adaptations school nuses can recommend are: (a) encourage the child to repeat the names of items or objects, (b) discuss relationships such as "first", "then", and "last", (c) sound field amplification, and (d) repeat what the child has incorrectly said using the correct grammatical form (Davis, 1989). 
Socially, a child with a hearing loss can exhibit over activity, distractibility and inappropriate responses or behavior. School nurses can be alert to observing and assessing these behaviors. If present, school nurses can recommend: (a) goal directional tasks to produce a positive, desired outcome, (b) seating to provide as few auditory and visual distractions as possible, (c) calling the child's name to bring the child back to task, and (d) encouraging interactive play involving communication and social skills (Davis, 1989).

Once a child is identified as having a hearing loss, the school nurse becomes the case manager for that child. It is critical that the school nurse work with the team toward meeting the child's educational needs. Open communication and a good working relationship between parents, teachers, medical and/or audiological care givers, and the school nurse is essential for the child with hearing loss. 
REFERENCES 


\section{References}

Anderson, K. L. (1987). When a child's hearing comes and goes. Principal, 67(2), 44-46.

Berg, F. S. (1987). Eacilitating classroom listening. A textbook for teachers of normal and hard of hearing students. San Diego: College-Hill.

Bernardo, I. (Ed.). (1993, March). South Bay Elementary and Unified School Districts. (Available from Bay Area Parent. 401 Alberto Way, Suite A. Los Gatos, CA 95032).

Bess, F. H. (1985). The minimally hearing-impaired child. Ear and Hearing, 6, 43-37.

Bess, F. H. (1992). Screening school-aged children for auditory function. Hearing less in childhood: A primer. Ohio: Ross Laboratories.

Bess, F. J., \& McConnell, F. E. (1981) Audiolegy, education and the hearing impaired child. St. Louis: Mosby.

Blair, J. C., Peterson, M. E., \& Viehweg, S. H. (1985). The effects of mild sensorineural hearing loss on academic performance of young school-age children. Velta Review, $\underline{87}(2), 87-93$.

Bloom, B. S. (1988). Helping all children learn in elementary school and beyond. Principal, 67(4), 12-17. 
Bluestone, C. D., Klein, J. O., Paradise, J. L., Eichenwald, J., Bess, F. H., Downs, M. P., Green M., Berko-Gleason, J., Ventry, I. M., Gray, S. W., McWilliams, B. J., \& Gates, G. A. (1983). Workshop on effects of otitis media on the child. Pediatrics, 71, 639-651.

Brandes, P. J., \& Ehinger, D. M. (1981). The effects of early middle ear pathology on auditory perception and academic achievement. Journal of Speech and Hearing Disorders, 46, 301-307.

Burgener, G. W., \& Mouw, J. T. (1982). Minimal hearing loss effect on academic/intellectual performance of children. Hearing Instruments, 33, 7-17.

Burns, N., \& Grove, S. K. (1987). The practice of nursing research: conduct, critique and utilization. Philadelphia: W. B. Saunders. California Administrative Code of 1986, Title 17, Health Code, Section 2951.

Davis, D. S. (1989). Otitis media: Coping with the effects in the classroom. New Jersey: Hear You Are, Inc. Department of Health Services: Maternal and Child Health Branch (1990). Manual for school audiometrist. Sacramento, CA: Author. Destephano-Lewis, K., \& Thomson, J. B. (1986). Manual of scheol health. California: Addison-Wesley. 
Dobie, R. A., \& Berlin, C. I. (1979). Influence of otitis media on hearing and development. Annals of otology, Rhinology and Laryngology, 88, 46-63.

Dworken, P. H. (1985). Learning and behavior problems of school children. Philadelphia: Saunders.

Eimas, P. D., \& Kavanaugh, J. F. (1986). Otitis media, hearing loss, and child development: A national institute of child health and development conference summary. Public Health Reports, 101(3), 289-293.

Fischler, R. S., Todd. W., \& Feldman, C. M. (1985). Otitis media and language performance in a cohort of Apache Indian chilaren. American Jourmal of Diseases of Chilaren, 132, 355-360.

Flexer, C., Wray, D., \& Ireland, J. (1989). Preferential seating is not enough: Issues in classroom management of hearing-impaired students. Language, Speech and Hearing Services in Schools, 20, 11-21.

Heathington, B. S., \& Alexander, J. E. (1984). Do classroom teachers emphasize attitudes toward reading? The Reading Teacher, 37, 484-488.

Johnston, E. B., \& Johnston, A. V. (1984). The Rigetian language nursery: An intensive group language intervention orogram for preschoolers. Maryland: Aspen. 
Kaplan, G. J., Fleshman, D. J., Bender, J. R., Baun, C., \& Clark, P. S. (1973). Long term effects of otitis media: A 10 year cohort study of Alaskan Eskimo children. Rediatrics, 52, 577-585.

Kavanaugh, J. F., (1986). Otitis media and child development. Parkton: York Press.

Lemer, J. W. (1988). Learning disabilities: Theories, diagnosis and teaching strategies (5th ed.). Palo Alto: Houghton-Mifflin.

LoBiondo-Wood, G., \& Harber, J., (1990). Nursing research: Methods, critical appraisal, and utilization (2nd ed.). St. Louis: Mosby.

Menyuk, P. (1980). Effects of persistent otitis media on language development. Annals of otology, Rhinology and Laryngology, 89 (Supp1. 68), 257-263.

Pulaski, M. A. (1980). Understanding Piaget: An introduction to childrens cognitive development. New York: Harper \& Row.

Roberts, J. E., Burchinal, M. R., Collier, A. M., Ramey, C. T., Koch, M. A., \& Henderson, F. W. (1989). Otitis media in early childhood and cognitive, academic, and classroom performance of the school-aged child. Rediatrics, 83, 477-485. 
Roberts, J. E., Sanyal, M. A., Burchinal, M. R., Collier, A. M., Ramey, C. T., \& Henderson, F.W. (1986). Otitis media in early childhood and its relationship to later verbal and academic performance. Rediatrics, 78, 423-430.

Roeser, R. J., \& Downs, M. P. (1981) Auditory disorders in school children: The law, identification, remediation. New York: Thieme-Stratton.

Sak, R. J., \& Ruben, R. J. (1981). Recurrent middle ear effusion in childhood: Implications of temporary auditory deprivation for language and learning. Annals of otelegy, 20, 546-550.

Salinger, T. S. (1985). Study skills: A "basic" in elementary reading instruction. Reading Improvement, $20,333-37$.

Skinner, M. W. (1978). The learning of speech during language acquisition. etolarngologic clinics of North America, 11, 631-649.

Stata, K. (1988). Improving hearing screening programs in the elementary school. School Nurse, 3, 16-19.

Ventry, I. M., (1980) Effects of conductive hearing loss: Fact or fiction. Journal of speech and Hearing Disorders, 45, 143-156. 
Zanga, Z. O. , \& Oda, D. S. (1987). School health services. Journal of School Health, 57, 413-416.

Zinkus, P. W., \& Gottlieb, M. I. (1980). Patterns of perceptual and academic deficits related to early chronic otitis media. Rediatrics, 66, 246-253. 
APPENDICES

59 
APPENDIX A

Approval by San Jose State University Human Subjects Institutional Review Board 
Erom:

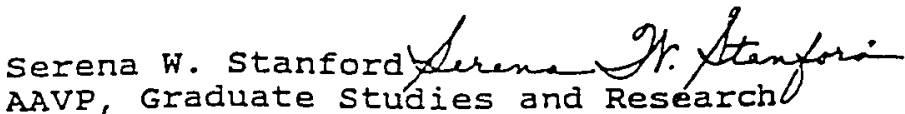

Date: June 10, 1993

The Human Subjects-Institutional Review Board has reviewed and approved your request for exemption from Insan Subjects Review for the proposed study entitled:

"The relationship between mild to moderate hearing loss and academic achievement in reading in elementary school children"

Provided that theie are no changes in the procedure proposed, you may proceed with this study without further review by the Human subjects-Institutional Review Board. You must notify the Human subjects-Institutional Peview Board of any changes in the subject population or procedure for this study

I do caution you, however, that Federal and state statutes and University policy require investigators conducting research under exempt categories to be knowledgeable of and comply with Federal and state regulations for the protection of human subjecis ir fesearci. This inciudes providing necessary information to enable people to make an informed decision regarding participation in your study. Further, whenever people participate in your research as human subjects, they should be appropriately protected from risk. This includes the protection of the confidentiality of all data that may be collected from the subjects. If at any time a subject becomes injured or complains of injury, you must notify Dr. Serena stanford immediately. Injury includes but is not limited to bodily harm, psychological trauma and release of potentially damaging personal information.

If you have questions, please contact me at 408-924-2480. 
APPENDIX B

Approval for research project from

Los Gatos Union School District 


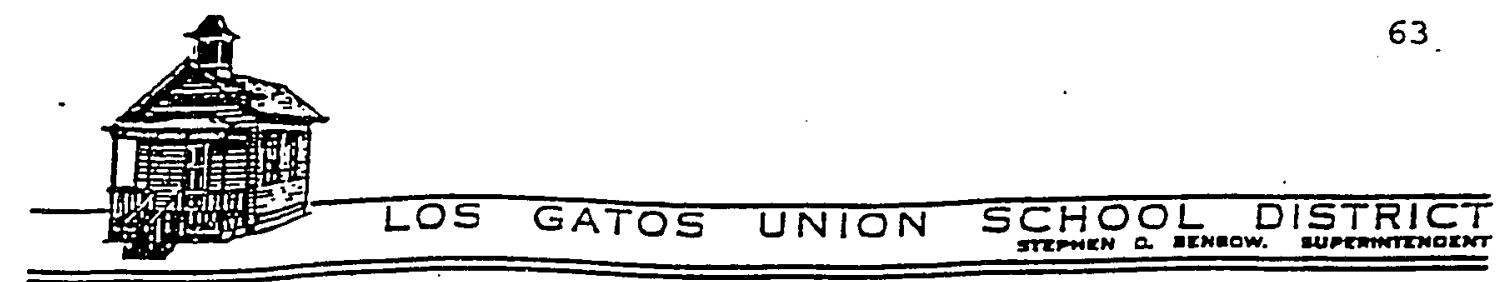

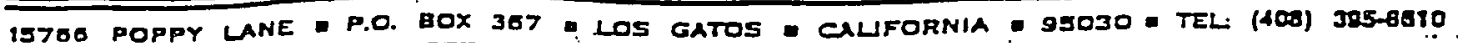
KAY MCOONALD, DIRECTOR SPECAL EUUCATIONPROJECTS

January 28, 1993

Maureen P. O'Hara

Dear Ms. O'Hara,

This letter is to give permission to Maureen O'Hara to gather information in the Los Gatos Union School District for her Masters Thesis for San Jose Slate University.

The project, which is limited to obtaining existing data through a chart review, is to examine the relationship between mild to moderate hearing loss in elementary aged children and their academic achievement in reading skills.

Confidentiality must be maintained and only group data may be complied i $;$. and reported.

I would indeed like to see the results of your study. Good luck in your project.

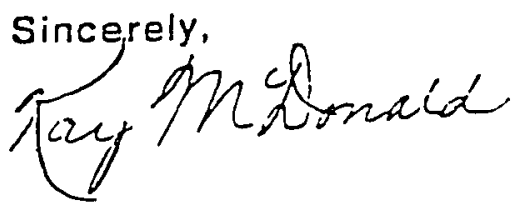

Kay McDonald

Director Special Education/Projects 
APPENDIX C

Collection Form A for review of existing records by classroom from schools 
Collection form $A$

for review of existing records

by classroom from schools

$\begin{array}{lll}\text { Subject } & \text { Subject } & \text { School code } \\ \text { Number } & \text { Name } & \end{array}$

\section{1.}

02 .

03.

04.

05.

06.

07.

08.

09.

10.

11.

12 .

13.

14.

15.

16.

17.

18.

19.

20. 
APPENDIX D

Collection Form $B$

Code Numbers for Classroom Records

Reviewed by School Year, Grade in School

Name of School 
Collection Form B

Code Numbers for Classroom Records

Reviewed by School Year, Grade in School

Name of School

\begin{tabular}{|c|c|c|c|c|c|c|}
\hline \multirow{2}{*}{$\begin{array}{l}\text { School Year } \\
\text { Name of } \\
\text { School }\end{array}$} & \multicolumn{2}{|c|}{$1990-91$} & \multicolumn{2}{|c|}{$1991-92$} & \multicolumn{2}{|c|}{$1992-93$} \\
\hline & $\begin{array}{l}2 \mathrm{nd} \\
\mathrm{Gr} .\end{array}$ & $\begin{array}{l}5 \text { th } \\
\text { Gr. }\end{array}$ & $\begin{array}{l}2 \mathrm{nd} \\
\mathrm{Gr} \text {. }\end{array}$ & $\begin{array}{l}5 \text { th } \\
\text { Gr. }\end{array}$ & $\begin{array}{l}\text { 2nd } \\
\text { Gr. }\end{array}$ & $\begin{array}{l}5 \text { th } \\
\text { Gr. }\end{array}$ \\
\hline \multirow[t]{3}{*}{ A } & 01 & 51 & 11 & 61 & 21 & 71 \\
\hline & 02 & 52 & 12 & 62 & 22 & 72 \\
\hline & 03 & 53 & 13 & 63 & 23 & 73 \\
\hline \multirow[t]{3}{*}{ B } & 04 & 54 & 14 & 64 & 24 & 74 \\
\hline & 05 & 55 & 15 & 65 & 25 & 75 \\
\hline & 06 & 56 & 16 & 66 & 26 & 76 \\
\hline \multirow[t]{3}{*}{ C } & 07 & 57 & 17 & 67 & 27 & 77 \\
\hline & 08 & 58 & 18 & 68 & 28 & 78 \\
\hline & 09 & 59 & 19 & 69 & 29 & 79 \\
\hline$D$ & 10 & 60 & 20 & 70 & 30 & 80 \\
\hline
\end{tabular}


APDFNDIX E Collection Form $C$ for review of existing health and cumulative folders 


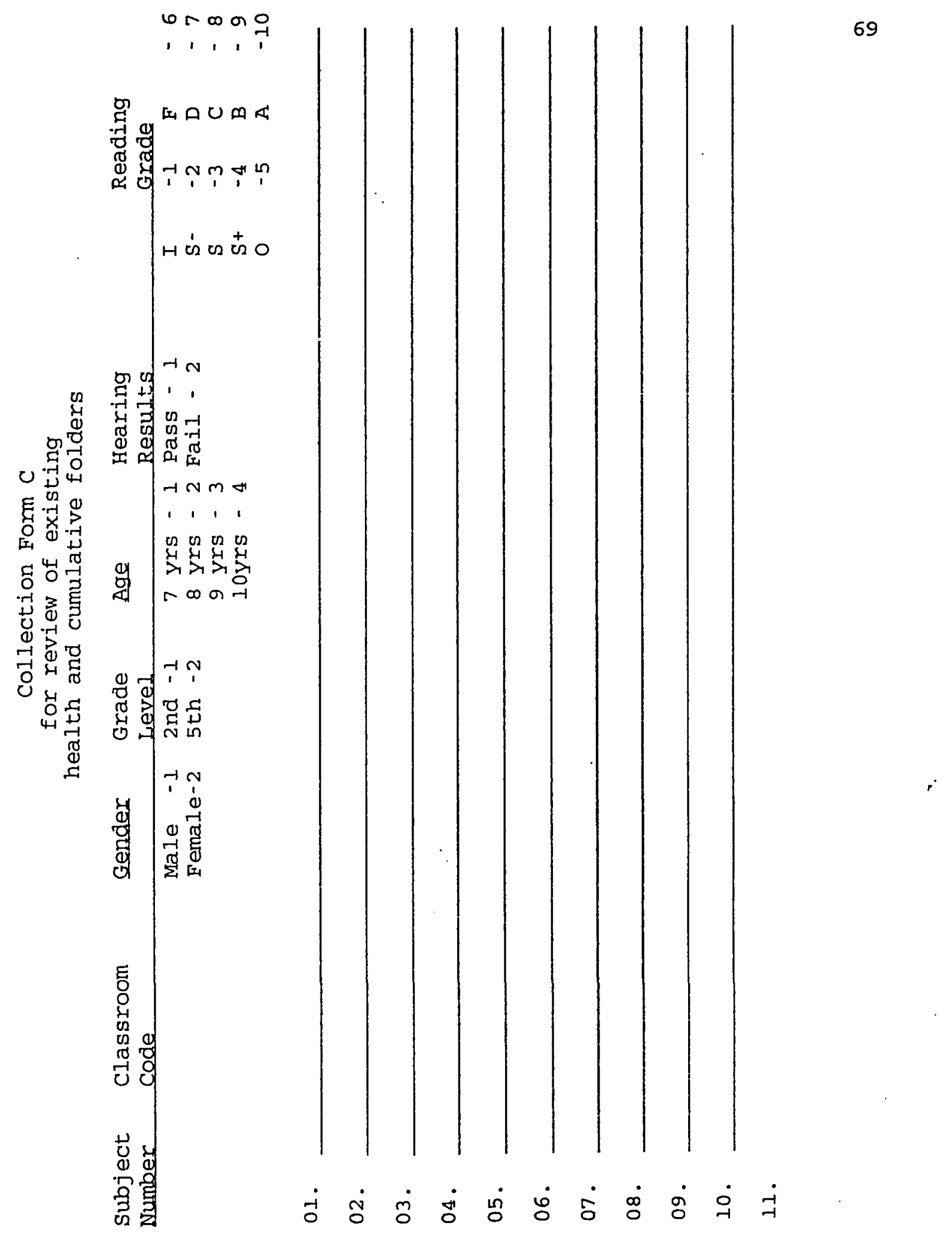

